\title{
İnce Barsak Hastalıklarında Enteroklizis'in Tanı Değeri
}

\author{
The Diagnostic Value of Enteroclysis in Small Bowel Disease
}

\section{Emine Öztürk', Cüneyt Yücesoy', Yıldıran Songürr, Alper Dilli', Tahsin Edgüer', Meltem Özdemir', Baki Hekimoğlu'} 'S.B.Dışkapı Yıldırım Beyazıt Eğitim ve Araştırma Hastanesi,
Radyoloji Kliniği

${ }^{2}$ S.B.Dışkapı Yıldırım Beyazıt Eğitim ve Araştırma Hastanesi, Gastroenteroloji Kliniği
Başvuru tarihi: 12.02.2010 • Kabul tarihi: 11.05.2010

İletişim

Emine Öztürk

S.B. Dışkapı Yıldırım Beyazıt Eğitim ve Araştırma Hastanesi Radyoloji Kliniği

:05334229271

E-Posta Adresi : ozturkemn@yahoo.com

Amaç: Ince barsak hastalıklarında enteroklizisin tanısındaki değerini araştırmak.

Gereç-Yöntem: Üst ve alt gastrointestinal sistem değerlendirmesi ile nedeni açıklanamayan abdominal ağrılar, kronik diare, nedeni açıklanamayan ancak primer ince barsak hastalığı olasılığı taşıyan kilo kaybı, halsizlik, anemi gibi yakınma ve bulguları olan yaşları 15-84 (ort yaş 47.5) arasında değişen 9'u erkek, 7'si kadın toplam16 hastaya; baryum sülfat ve metil sellüloz eriyiğinin kullanıldığı Herlinger tekniği ile çift kontrast enteroklizis incelemesi yapıldı.

Bulgular: Dört olguda malabsorbsiyon bulguları (ince barsak segmentlerinde dilatasyon, motilitede artış, mukozal sıvanmada azalma), Crohn hastalığı tanısı alan 3 olgudan ikisinde; terminal ileumde rijidite, distal kesimde ülserler, bir olguda kolon $1 \frac{1}{2}$ distal kesiminde haustrasyon kaybı izlendi. Bir olguda askarise ait dolum defekti, 1 olguda çekum kitlesinin invazyonuna sekonder terminal ileumda rijidite ve mukozal düzensizlik, 1 olguda foldlarda kalınlaşma, 2 olguda ince barsak segmentlerine dıştan bası bulgusu, 2 olguda normal bulgular, 1 olguda motilitede azalma, 1 olguda terminal ileumda geçirilmiş operasyona sekonder değişiklikler izlendi.

Sonuç: Enteroklizis, endoskopik ve radyolojik inceleme olanaklarının sınırlı olduğu ince barsak hastalıklarının tanı ve ayıııcı tanısında yüksek doğruluk oranlarına sahip, oldukça duyarlı bir inceleme yöntemidir.

Anahtar Sözcükler: Ince barsak, Enteroklizis, Metil sellüloz

Objective: To Investigate The Diagnostic Value of Enteroclysis in Small Intestine Diseases.

Material and Method: A total of 16 patients, 9 of which were male and 7 of which were female with an age range from 15 to 84 ( avarage 47.5) with abdominal pain which could not be explained by examining the upper and lower gastrointestinal system, chronic diarrhea, obcsure weight loss but suspected small intestine disease, asthenia, anemia, were investigated with double contrast enteroclysis examination using Herlinger method in which barium sulphate and methyl cellulose solution were used.

Results: In four cases malabsorbion findings (dilation in small intestine segments, increase in motility, decrease in mucosal involvement); in 2 out of 3 cases with known Crohn disease rigidity in terminal ileum, ulcers in distal part; in one case loss of haustration in dismal half of the colon were detected. In one case filling defect by an ascaris; in one case rigidity in secondary terminal ileum to the invasion of cecum tumor and mucosal disorder; in one case thickening of folds; in two cases findings of external impression to small intestine segments; in two cases normal findings; in one case decrease in motility; in one case secondary changes to the operation in the terminal ileum were detected.

Conclusion: Enteroclysis is an highly sensitive method of examination which has high accuracy rates at the diagnosis and differential diagnosis of small intestine diseases whose endoscopic and radiological examinations are limited.

Key Words : Small intestine, Enteroclysis, Methyl cellulose

Anatomisi ve lokalizasyonu nedeniyle ince barsak, gastrointestinal sistemin radyolojik olarak incelenmesi en zor kısmıdır. Bu uzun, aralıklı olarak kasılan, s1nırlı bir alanda kendi üzerine dolanmış, sıvı içeren organın mukozal detayını de- monstre etmek ise daha da zordur.

Baryumlu grafiler, ultrasonografi (US), bilgisayarlı tomografi (BT) ve Manyetik rezonans (MR) görüntüleme, anjiografi ince barsakların radyolojik in- 
celemesinde kullanilan modalitelerdir. Yeni görüntüleme metodları, ince barsağın değerlendirilmesinde radyolojiye ek boyutlar getirmiştir. Ağızdan verilen baryum ile yapilan ince barsak tetkiki yerine, kateter aracıl l̆ğı ile kontrast maddenin doğrudan duodenojejunal bileşkeye verildiği selektif ince barsak tetkikleri, yani "enteroklizis", kullanılmaya başlanmıştır.

Enteroklizis, sadece baryum kullanılarak "tek kontrastlı enteroklizis" şeklinde 1971'de Sellink tarafından tanıtılmıştır (1). Kontrast madde olarak baryum ve ardından da metil sellüloz verilerek gerçekleştirilen "çift kontrastlı enteroklizis" yönteminin kullanılımını, Herlinger yaygınlaştırmıştır (2).

$\mathrm{Bu}$ çalışmada, karın ağrısı, diare, anemi, melana, parsiyel barsak tıkanıklığı gibi gastrointestinal sistem yakınma ve bulgularıyla başvuran olgularda enteroklizis tetkikiyle elde edilen radyolojik bulgular, klinik ve/veya histopatolojik kesin tanılar ile karşılaştırılarak, enteroklizis yönteminin ince barsak hastalıklarının tanısındaki değerinin araştırılması amaçlanmıştır.

\section{Gereç ve Yöntem}

Üst ve alt gastrointestinal sistemin radyolojik ve endoskopik muayenesi ile nedeni açıklanamayan abdominal ağrılar, kronik diare, nedeni açıklanamayan ancak primer ince barsak hastalığ 1 olasılığını taşıyan kilo kaybı, halsizlik, anemi gibi yakınma ve bulguları ile, bölümümüze çift kontrastlı enteroklizis ile tetkik için gönderilen 16 hasta, endikasyon protokolü dahilinde çalışmaya alındı. Olguların 9'u erkek, 7'si kadın olup, yaşları 15-84 arasında değişiyordu (ortalama yaş: 47.5).

Olguların klinik izlemleri sırasında işlem öncesi tüm hastalara ultrasonografi, 3 olguya işlem sonrası bilgisayarlı tomografi (BT) ve 1 olguya işlem sonrası üst gastrointestinal sistemin baryumlu incelemesi uyguland.

İnce barsağın enteroklizis yöntemi ile incelenmesinde, \%80'lik baryum sülfat ve
$\% 5^{\prime}$ lik metil sellüloz eriyiğinin kullanıldığı Herlinger tekniği esas olarak alındı.

Hastalara tetkikten bir gün önce çekum ve sağ hemikolonun temizlenmesi amacıyla bol sivili, posa birakmayan gidalar almaları önerildi. Böylece çekumun da incelenmesi sağlandı.

Aşağıdaki malzemeler tetkik öncesinde hazırlandi:

1. Baryum sülfat (Ba SO4) solüsyonu:

$\% 80 \mathrm{w} / \mathrm{v}$ konsantrasyonda $250-300 \mathrm{ml} \mathrm{Ba}$ SO4 hazırlanarak 50 ml'lik enjektörlere çekildi.

\section{Metil sellüloz solüsyonu:}

Metil sellüloz eriyiğinin hazırlanışında; 10 gramlık metil sellüloz tozu yaklaşık 85-90 C derecede $400 \mathrm{ml}$ su ile, toz iyice sslanıp karışıncaya kadar, karıştırılarak ısıtıldı. Daha sonra 1.6 lt'ye ulaşıncaya kadar soğuk su eklendi. Solüsyonun fungostatik aktivitesinin olmaması nedeniyle, eğer hemen kullanilmayacaksa buzdolabında saklandi. Kullanımdan önce tüm solüsyonun oda ısısında olması sağlanacak şekilde $400 \mathrm{ml}$ llık su ilave edildi ve $50 \mathrm{ml}$ lik enjektörlere çekildi.

\section{Maglinte balon enteroklizis seti:}

$160 \mathrm{~cm}$ uzunluğunda 13 French çapında, 6 yan delik ve reflüyü önleyici lateks balona sahip polivinilklorid kateter ve teflon kaplı kılavuz telden oluşan sonda hazırlandi.

\section{4. \%20 lik benzocaine:}

Peroral kateterizasyon öncesinde orofarinkste topikal anestezi için sağlandı.

10 mg'lik metoclopramide, mide tonusu ve motilitesini arttırmak, piloru gevşetmek amaciyla IV vermek üzere hazırlandi.

Peroral kateterizasyon öncesinde orofarinkse \%20'lik benzocaine ile topikal anestezi uygulandi. Hasta oturur pozisyonda, baş hiperfleksiyonda iken peroral yolla kateter yutturuldu ve yutkunma refleksiyle oluşan peristaltik dalgalar ile mideye kadar iler- letildi. Kateterin ösafagusta takılması durumunda kateter biraz geri çekilerek veya kateterin geri çekilmesi s1rasında k1lavuz telin ilerletilmesinden oluşan "double back manevra" ile kateter düzleştirildi.

Kardiyaya ulaşıldığında duodenuma geçiş görülünceye kadar floroskopik olarak kateterin ilerletilmesi takip edildi. Transgastrik pasaj için hasta sağ lateral dekubitus pozisyonuna yatırılarak floroskopik baskı altında kateterin büyük kurvatura yaslanarak ilerlemesi ve pilordan geçerek duodenuma yönlenmesi sağlandı. Kateter mide fundusunda veya antrumda kıvrıldığında, doubleback manevrasindan yararlanıldı.

Uygulamalarımızda pilordan geçişte zorluk ile karşılaşıldığında; hasta sol lateral dekubitus pozisyonunda yatır1lıp bulbus duodeninin hava ile dolması sağlandı. Yeterli distansiyon sağlanmadığında ise hava enjekte edilerek bu pozisyonda superior duodenal fleksura da açıldığından kateterin duodenum içinde kolaylıkla ilerlemesi sağlandi. İnferior duodenal fleksuradan geçişte zorluk ile karşılaşıldığında tekrar double-back manevrasından yararlanild.

Duodenojejunal bileşkede zorluk ile karşılaştığımızda hasta diz dirsek pozisyonuna getirildi, böylece retroperitoneal duodenal parça rahatlayarak lümenin genişlemesi sağlandi. Ancak bu pozisyonun uygulanmasinı tolere edemeyen hastalar sol semipron pozisyonda yatırilarak derin inspriumda ve hasta öksürtülerek jejunuma geçiş sağlandı.

Proksimal jejenuma ulaşıldıktan sonra kateterin distalindeki balon $18 \mathrm{cc}$. hava enjekte edilerek şişirildi, böylece uygulanacak baryum ve metil sellülozun duodenum ve mideye reflüsü engellendi.

Kateterin dışarıda kalan ucundan yaklaşık 200-250 cc. $\% 80 \mathrm{w} / \mathrm{v}$ volümlük baryum sülfat solüsyonu 50 ml'lik enjektörlerle dakikada ortalama $75 \mathrm{ml}$. hizla gönderildi. Kontrast maddenin veriliş hızı hastanın barsak motilitesine göre ayarland. Malabsorbsiyon gibi barsak sekresyonlarının arttığı durumlar- 
da verilen kontrast madde miktarı da arttırild.

İleumun tüm segmentlerinin baryum ile dolduğu floroskopik olarak görüldükten sonra \% 0.5 lik hidroksi-propilmetil selüloz dakikada 80-100 ml. hızla enjekte edildi. Tüm ince barsak ansları gerilip çift kontrastlı görüntü sağlanıncaya kadar enjeksiyon sürdürüldü. Genellikle yaklaşık 1500-2000 ml. metil sellüloz, terminal ileuma kadar ince barsakların çift kontrastlı görüntülerini elde etmek için yeterli oldu. Soğuk solüsyonlar, peristaltizmi hizlandırıp reflüye, hastanın kusmasına ve kramp şeklinde karın ağrılarına sebep olacağından, baryum ve metil sellüloz solüsyonlarının ısısının yaklaşık vücut sıcaklığında olmasına dikkat edildi ve bu amaçla her iki solüsyon tetkik öncesi isitıldi.

Metil sellüloz enjeksiyonunda önce tek kontrastlı fazda skopik olarak barsak motilitesi değerlendirildi ve patolojik herhangi bir lezyon kuşkusu mevcut değil ise grafi alınmadı.

Metil sellüloz enjeksiyonundan sonra, yani çift kontrastlı fazda terminal ileum ve uygun görülen ansların spot grafileri alınd. Gereğinde kompresyon uyguland, jejunal ve proksimal ileal ansların değerlendirilmesi için hasta hafif sağa, distal ileal anslar için ise sola döndürüldü. Pelvik yerleşimli ileal ansları değerlendirmek için lateral ve trendelenburg pozisyonunda kompresyonlu grafiler çekildi. Tetkik sonunda, prone pozisyonda masa üstü filmi alındı.

Kateter balonundaki hava aspire edilerek kateter geri çekildi ve işleme son verildi (Duodenumun görüntülenmesi gereken olgularda kateter duodenum orta kesimine kadar geri çekilerek baryum ve metilsellüloz verilerek spot grafiler alınır. Mideye yoğun reflü izlenen olgularda da kateter mideye kadar geri çekilerek mide içeriği aspire edilir).

Olgu grubunun değerlendirilmesinde, skopi sırasında ince barsakların motilitesi ve geçiş süresi incelendi. Elde olunan radyogramlarda jejunum ve ileum anslarının lümen genişlikleri, duvar

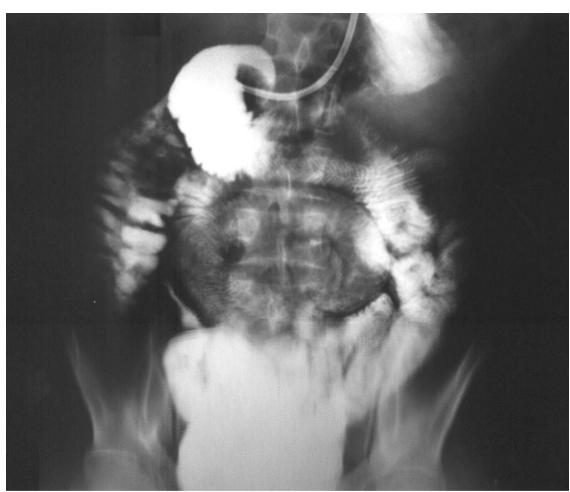

Şekil 1: Orta jejunal ve ileal segmentlerde seperasyon, terminal ileumda düzensiz konturlu daralma izlenmektedir. Bu bulguların mezenterik tüberküloza sekonder olduğu saptandı.

kalınlıkları ve konturları; plika sirkülarislerin sayısı ve kalınlığı; plikalar arası mesafeler ve mukozal pattern değerlendirildi ve intraluminal dolum defekti veya fazlalığının, ekstra lüminal basının ve parsiyel veya total obstrüksiyonun varlığı araştırıldı.

\section{Bulgular}

Radyolojik olarak patolojik lezyon saptanan olguların en geniş alt grubunu malabsorbsiyon olguları oluşturmaktaydı. Kronik diare, kusma, malabsorsiyon kliniği ile başvuran dört hastanın değerlendirilmesinde; olguların tümünde ince barsak segmentlerinde dilatasyon, üç olguda motilitede artış saptanırken, bir olguda motilitede azalma, iki olguda mukozal sıvanmada azalma saptandi.

Yaygın karın ağrısı şikayeti ile başvuran,
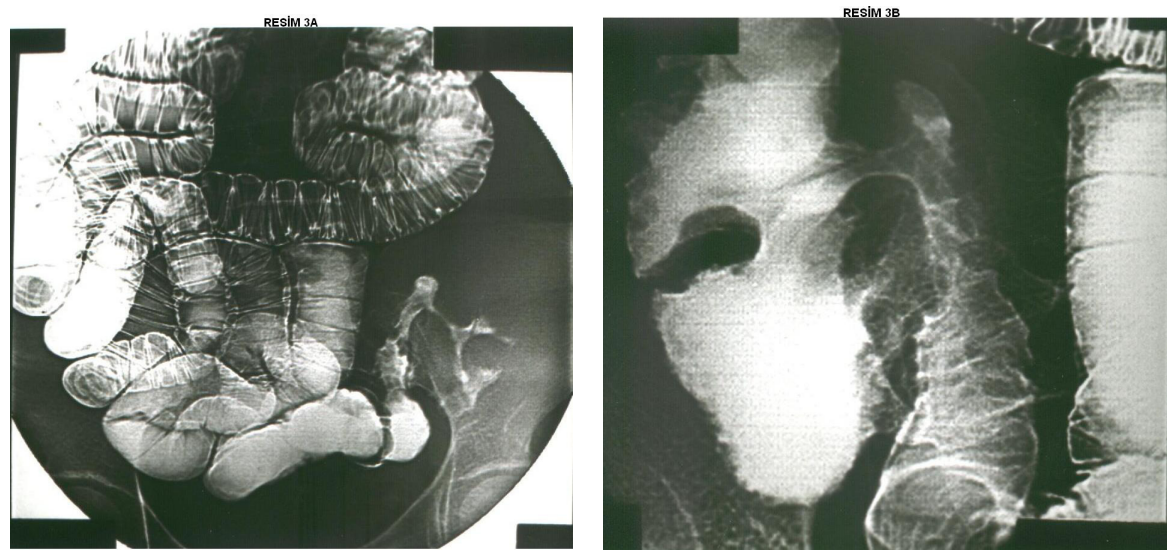

Şekil 3(a, b) : Crohn hastalığı tanısı alan olgunun pron pozisyonda alınan erken dönem grafisinde; jejunal ve proksimal ileal segmentlerinin normal olduğu, terminal ileumda mukozal düzensizlik (oklar) (a), geç dönem grafisinde ise terminal ileumda kaldırım taşı görünümü (oklar) ve terminal ileumun kolonik duvarında (gül dikeni) ülserler (oklar) izleniyor. 
ve metilsellülozun kolon segmentlerini doldurmasını takiben alınan grafilerde; transvers kolon orta kesiminin distalindeki kolon segmentlerinde haustrasyon kaybı ve rijidite varlığı saptandı (Şekil 2). Üçüncü olguda ise terminal ileum konturlarında ülserlere (gül dikeni şeklinde) sekonder düzensizlik ve mukozal nodüllere bağlı kaldırım taşı manzarası izlendi (Şekil 3 a, b).

Üst gastrointestinal sistemi ve kolonun konvansiyonel incelemelerinde pozitif bulgu saptanmayan kronik karın ağrısı şikayeti ile başvuran olgunun enteroklizis tetkikinin tek ve çift kontrast aşamalarında tüm ileal segmentlerde askarise ait lineer dolma defektleri saptandı (Şekil 4).

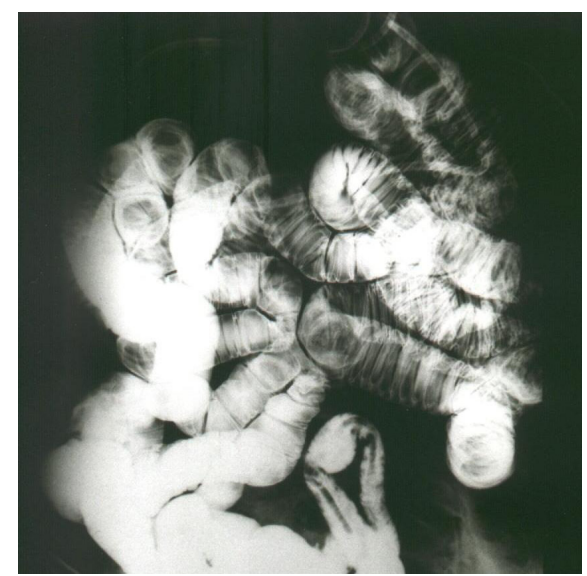

Şekil 4: Kronik karın ağrısı ile araştırılan olgunun ileal anslarında askarise ait dolum defekti izleniyor.

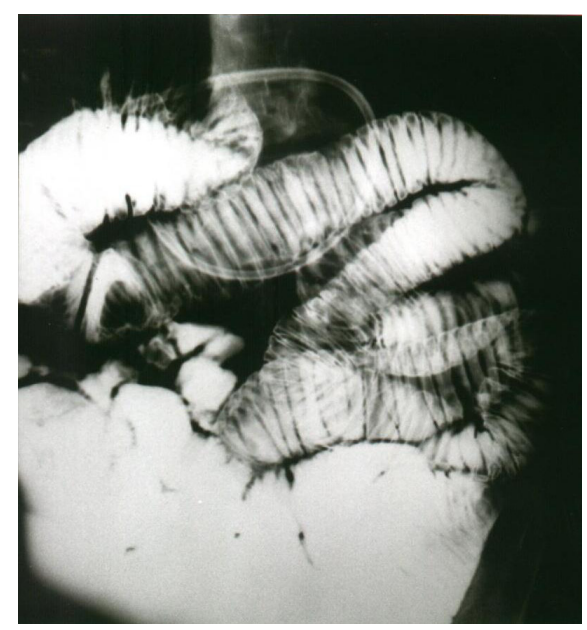

Şekil 5: İntestinal lenfoma tanısı alan olgunun jejunal segmentlerinde yaygın pili kalınlaşması izleniyor.
Sağ alt kadran ağrısı etiyolojisi araştırılan olgunun enteroklizis incelemesinde floroskopik olarak pasajda yavaşlama, ince barsak anslarında minimal dilatasyon (lümen çapı üst sınırda), terminal ileumda rijidite, mukozal düzensizlik saptandı.

İntestinal lenfomanın araştırıldığı karın ağrısı, kilo kaybı şikayeti ile enteroklizis tetkikine alınan olguda jejunal segmentlerde dilatasyon ve pililerde diffüz kalınlaşma (3 mm) saptandı (Şekil 5).

Kilo kaybı, karın ağrısı ile radyoloji kliniğine refere edilen olgunun enteroklizis tetkikinde kateterizasyon sırasında duodenum birinci ve ikinci kısmında zorluk ile karşılaşıldı. Enteroklizis ile jejunum ve ileum segmentlerinin normal olarak değerlendirilmesini takiben kateter mideye kadar geri çekildi; opak ilaç verilerek alınan grafilerde duodenum birinci ve ikinci kısım lümeninin eksternal basıya bağlı daraldığı saptandı.

Üç yıl önce gastrik operasyon geçiren postprandial ağrı, bulantı, kusma şikayetleri nedeniyle subileus ön tanısı düşünülerek incelemeye alınan hastanın enteroklizis tetkikinde ince barsak segmentleri lümen çapları, duvar kalınlıkları, pili sayı ve kalınlıkları normal olup motilitede azalma dışında bir bulgu saptanmadi.

Behçet hastalığı nedeni ile takipte olan, iki yıl önce ileal ülserlere sekonder gelişen intestinal perforasyon sebebiyle opere edilen (terminal ileum rezeksiyonu ve ileokolostomi) hastanın kontrol amacıyla yapilan enteroklizis incelemesinde; jejunal ve proksimal ileal segmentler normal olarak izlendi. Terminal ileumun rezeke edilmiş ve kalan ileum segmentinin çıkan kolon orta kesimine ağızlaştırılmış olduğu saptandı.

Kronik diare, karın ağrısı nedeni ile tetkik edilen iki olgunun enteroklizis bulguları normal olarak değerlendirildi.

Olgulara ait klinik ve radyolojik bulgular tabloda özetlendi (Tablo 1).

\section{Tartışma}

Gastrointestinal sistemin radyolojik olarak değerlendirilmesinde ince barsaklar, anatomik ve fizyolojik özellikleri nedeniyle, en çok sorun yaratan bölümdür. İnce barsak pasaj grafilerinde fizyolojik bir bariyer olan pilor, oral yolla verilen kontrast maddenin geçiş hızını azaltmakta ve barsakların yeterli dilatasyonuna engel olmaktadır. Ek olarak transit süresinin uzun olduğu veya sekresyonun arttığı durumlarda, kontrast maddenin flokulasyonu ve segmentasyonu neticesinde, mukozal yüzeyin ve ansların detaylı incelenmesi konvansiyonel ince barsak tetkikinde yanlış yorumlara neden olabilmektedir (3).

Enteroklizis, yaygın olarak kullanılan ancak yukarıda sözü edilen dezavantajlara sahip konvansiyonel ince barsak pasaj grafilerinin yerine tercih edilmektedir. Çift kontrast enteroklizis ilk kez Herlinger tarafından 1978 yılında uygulanmıştır. Bu tetkikte çift kontrast görüntü metil sellüloz ile sağlanmıştır (2). Baryum enjeksiyonunu takiben verilen metil sellüloz, önündeki baryumu iterek (baryum içine diffüzyonu az olduğu için) barsak lümeninin genişlemesini ve kontrastın mukozaya adezyonunu sağlar. Metil sellüloz eriyiğinin transparan özelliği sayesinde, özellikle pelvik yerleşimli ince barsak ansları süperpozisyonlarına rağmen iyi görüntülenirler. Ayrica metil sellüloz absorbe olmaz ve laksatif etkisi nedeniyle baryumun katılaşmadan atılmasını sağlar.

Enteroklizis tekniğinin ince barsak hastalıklarının tanısındaki değerinin araştırıldığı çalışmamıza alınan 16 olgunun 2'inde enteroklizis normal olarak değerlendirilmiştir. Klinik ileri tetkiklerde ve izlemde bu olguların hiçbirinde ince barsakta patolojik lezyon saptanmamıştır. Bu sonuç da, literatürde vurgulandığ 1 gibi, enteroklizis tekniğinin yüksek gerçek negatiflik özelliğini yansıtmaktadır $(4,5)$. Bu 2 olgumuz histopatolojik olarak nonspesifik kolon inflamasyonu tanısı aldı ve şikayetleri bu taniya sekonder olarak değerlendirildi.

Malabsorbsiyon tanısı klinik bulgulara ve biyokimyasal testlere dayanarak konulur. Klinik olarak malabsorbsiyon sap- 
Tablo: Olgulara ait klinik ve radyolojik bulgular

\begin{tabular}{|c|c|c|c|c|c|}
\hline Olgu No & Yaş & Cinsiyet & Şikayet & Enteroklizis bulguları & Tanı \\
\hline Olgu 1 & 30 & $\mathrm{~K}$ & Kronik ishal, kusma & $\begin{array}{l}\text { Intestinal motilite artışı, ince bar- } \\
\text { sak segmentlerinde dilatasyon, } \\
\text { mukozal sıvanmada azalma }\end{array}$ & Gluten Enteropatisi \\
\hline Olgu 2 & 16 & E & Kronik ishal & $\begin{array}{l}\text { Intestinal motilite artışı, ince bar- } \\
\text { sak segmentlerinde dilatasyon, } \\
\text { mukozal sıvanmada azalma }\end{array}$ & Gluten Enteropatisi \\
\hline Olgu 3 & 15 & $\mathrm{E}$ & Kronik ishal & $\begin{array}{l}\text { İntestinal motilitede azalma, bar- } \\
\text { sak segmentlerinde dilatasyon }\end{array}$ & Gluten Enteropatisi \\
\hline Olgu 4 & 22 & E & Kronik karın ağrısı & $\begin{array}{l}\text { Orta jejunal ve proksimal ileal seg- } \\
\text { mentlerde seperasyon, terminal il- } \\
\text { eumda düzensiz konturlu daralma }\end{array}$ & $\begin{array}{l}\text { Mezenterik Tüberkül- } \\
\mathrm{oz}\end{array}$ \\
\hline Olgu 5 & 33 & $\mathrm{~K}$ & $\begin{array}{l}\text { Kronik ishal, karın } \\
\text { ağrısı }\end{array}$ & Normal & $\begin{array}{l}\text { Ince barsak patolojisi } \\
\text { saptanmadı }\end{array}$ \\
\hline Olgu 6 & 39 & $\mathrm{~K}$ & $\begin{array}{l}\text { Kronik ishal, karın } \\
\text { ağrısı }\end{array}$ & Normal & $\begin{array}{l}\text { Ince barsak patolojisi } \\
\text { saptanmadı }\end{array}$ \\
\hline Olgu 7 & 22 & $\mathrm{~K}$ & Kanlı, mukuslu ishal & $\begin{array}{l}\text { Terminal ileumde rijidite, distal } \\
\text { kesimde ülserler }\end{array}$ & Crohn \\
\hline Olgu 8 & 51 & $E$ & Kanlı, mukuslu ishal & $\begin{array}{l}\text { Normal ince barsak segmentleri, } \\
\text { Kolon } 1 / 2 \text { distal kesiminde haustra- } \\
\text { syon kaybl }\end{array}$ & $\begin{array}{l}\text { Crohn (kolon tutu- } \\
\text { lumu) }\end{array}$ \\
\hline Olgu 9 & 56 & K & $\begin{array}{l}\text { Kanlı-mukuslu ishal, } \\
\text { karın ağrısı }\end{array}$ & $\begin{array}{l}\text { Terminal ileumda ülserler ve } \\
\text { kaldırım taşı görünümü }\end{array}$ & Crohn \\
\hline Olgu 10 & 35 & $\mathrm{~K}$ & Karın ağrısı & $\begin{array}{l}\text { İleal segmentlerde lineer dolum } \\
\text { defekti }\end{array}$ & Askariazis \\
\hline Olgu 11 & 76 & $E$ & $\begin{array}{l}\text { Sağ alt kadran } \\
\text { ağrısı }\end{array}$ & $\begin{array}{l}\text { Intestinal motilitede azalma, ince } \\
\text { barsak segmentlerinde hafif dila- } \\
\text { tasyon, terminal ileumda rijidite } \\
\text { ve mukozal düzensizlik, çekumda } \\
\text { mukozal destrüksiyon }\end{array}$ & $\begin{array}{l}\text { Çekum karsinomu- } \\
\text { nun terminal ileum } \\
\text { invazyonu }\end{array}$ \\
\hline Olgu 12 & 33 & E & $\begin{array}{l}\text { Kilo kaybı, karın } \\
\text { ağrısı }\end{array}$ & $\begin{array}{l}\text { Jejunal segmentlerde dilatasyon } \\
\text { ve pililerde kalınlaşma }\end{array}$ & İntestinal Lenfoma \\
\hline Olgu 13 & 58 & $E$ & Kronik ishal & $\begin{array}{l}\text { Intestinal motilitede artıs, ince bar- } \\
\text { sak segmentlerinde dilatasyon }\end{array}$ & $\begin{array}{l}\text { Diabetik otonom } \\
\text { nöropati }\end{array}$ \\
\hline Olgu 14 & 84 & E & $\begin{array}{l}\text { Kilo kaybı, karın } \\
\text { ağrısı }\end{array}$ & $\begin{array}{l}\text { düodenom } 1 \text {. ve } 2 \text {. kısmında dış } \\
\text { basıya bağlı daralma }\end{array}$ & Pankreas başı tümörü \\
\hline Olgu 15 & 38 & $\mathrm{E}$ & $\begin{array}{l}\text { Postprandial ağrı, } \\
\text { bulantı, kusma }\end{array}$ & İntestinal motilitede azalma & $\begin{array}{l}\text { Pyloroplasti+trunkal } \\
\text { vagotomi }\end{array}$ \\
\hline Olgu 16 & 62 & $\mathrm{~K}$ & Kronik ishal & $\begin{array}{l}\text { Terminal ileum } \\
\text { rezeksiyonu+ileokolostomi }\end{array}$ & Enterobehçet \\
\hline
\end{tabular}

tanan olgularda bunun demonstrasyonu veya malabsorbsiyonun sebebini saptamak ve olası komplikasyonları demonstre etmek için enteroklizis önerilen tetkiktir (6). Primer malabsorbsiyonun yanısıra, ince barsak hastalıklarına sekonder gelişen absorbsiyon bozuklukları da mevcuttur. Ancak klinik olarak malabsorbsiyon kuşkusu olmayan olgularda enteroklizis ile malabsorbsiyon tanısının konulması mümkün değildir. Diğer bir deyişle malabsorbsiyon tanısı için klinik destek şart- trr. Skopik incelemede motilitenin değerlendirilmesi ile barsak anslarında dilatasyon derecesine, plika sirkülarislerin sayısındaki değişikliklere (jejunumda azalması-psödokolonizasyon, ileumda artması-jejunizasyon), mukozal paternine (mozaik patern) bakılarak tanı konulabilir. Ayrıca, Çöliak hastalığına sekonder malignite gelişiminin saptanabilmesi açısından enteroklizis üstün bir yöntemdir (5).

Çalışmamızda malabsorbsiyon bulguları ile incelemeye alınan 4 olguda 3'ünde tanı konmuş çöliak hastalığı mevcut idi. Bu olgularda enteroklizis incelemesinde saptanan motilitede artış, ince barsak anslarında dilatasyon ve mukozal sıvanmada azalma 11 mlı malabsorbsiyona sekonder bulgular olarak yorumland. İnce barsak fold say1sında ve kalınlığında anlamlı değișiklik saptanmaması ise glutensiz diyete barsağın morfolojik cevabı değerlendirildi. Malabsorbsiyon bulguları ile incelenen diabetes mellitus tanısı olan son olgunun enteroklizis tetkikinde sapta- 
nan motilite artışı ve barsak segmentlerinde dilatasyonun otonomik nöropatiye sekonder değerlendirildi.

Crohn hastalığı, gastrointestinal sistemin herhangi bir segmentini tutabilen kronik inflamatuar bir proçestir. Klinik çalışmalar hastalığın ince barsağa sınırlı olduğu olgularda semptomların başlangıcı ile tanı arasındaki gecikmenin, en fazla olduğunu göstermektedir (7). $\mathrm{Bu}$ çalışmalarda ve diğer bazı yayınlarda aralıklı floroskopi ve kompresyonlar ile elde edilmiş takip ince barsak pasaj grafileri ile de ince barsağın Crohn hastalı̆̆ının tanısında tatminkar sonuçlar bildirilirken, enteroklizis ve takip ince barsak pasaj tetkiki arasındaki direkt karşılaştırmalar, enteroklizisin üstünlügünü göstermektedir (7-10).

Klinik olarak belirlenemeyen Crohn hastalığında enteroklizis, hastalığın varlığını ortaya koyması, tanı aşamasından sonra da hastalığın erken dönem bulgularını, yaygınlığını ve derecesini demonstre etmesi nedeni ile seçilecek spesifik baryumlu tetkik olarak kabul edilmektedir (11). Enteroklizis tekniği ile Crohn hastalığının mukozal veya submukozal evresine uyan erken dönem değişiklikler ve skip lezyonlar gösterilebilmektedir. Maglinte ve ark. tarafindan 1992 yilında yayınlanan 138 olguluk bir seride, enteroklizisin sensitivite, spesifisite ve doğruluk oranı, sırası ile $\% 100, \% 98.3$ olarak bildirilmektedir (7). Çalışmamızda Crohn hastalığı ön tanısı ile incelemeye aldığımız üç olgudan ikisinde erken dönem Crohn hastalığına ait terminal ileal değişiklikler saptandı.

İnce barsağın Crohn hastalığında ileri dönemde fibrozis ve barsak duvarındaki kalınlaşmaya bağlı striktürler gelişir. Yaygın ülserasyonun neden olduğu irritabiliteye bağlı spazm ve ödem ile oluşan "string sign", konvansiyonel pasaj grafilerinde gerçek striktürden ayırd edilemez. Ancak enteroklizisde metil sellüloz infüzyonu ile sağlanan barsak lümeninin distansiyonu sayesinde spazm veya ödeme bağlı darlık ile striktür kolaylıkla ayırd edilebilmektedir $(7,11)$. Bu ayırım da klinis- yene medikal veya cerrahi tedavi tercihinde yardımcı olmaktadır. Bir olgumuzda kolon segmentlerinde izlenen haustrasyon kaybı ve rijidite Crohn hastalığının kolon tutulumu olarak değerlendirldi.

Ayrıca obstrüksiyon, fistül gibi Crohn hastalığının komplikasyonları nedeniyle opere edilecek hastalarda ameliyat öncesi dönemde hastalığın yaygınlığının saptanmasında, ameliyat sonrası dönemde ise nüksün belirlenmesi, yaygınlığının ve evresinin değerlendirilmesi ve striktür/fistül gibi komplikasyonlarının ortaya konulmasında enteroklizis üstün bir yöntem olarak görünmektedir $(12,13)$. Enterik sinus traktlarının, fistüllerin görüntülenmesinde bilgisayarlı tomografi (BT) enteroklizisin, enteroklizise üstünlüğü bildirilmektedir $(14,15)$. Barsak duvarındaki ve barsak duvarı dışındaki (flegmon/abse) patolojileri ortaya koymada, BT ile daha iyi yapılabilmektedir (15). Olgularımızda enterik komplikasyona rastlanmadı.

Crohn hastalığında kateterizasyonlu magnetik rezonans (MR) enteroklizis yada sadece oral kontrast verilenerek yap1lan MR enterografinin değeri bildirilmektedir. Crohn hastalığında; MR enteroklizisin yüzeyel mukozal lezyonları değerlendirmede konvansiyonel enteroklizis ile karşılaştırılabilir değerde olduğu, konvansiyonel enteroklizisdeki radyasyon maruzuyitenden kaçınmak için MR enteroklizisin kullanılabileceği; MR enterografinin, konvansiyonel ve MR enteroklizisten daha az duyarlı olduğu vurgulanmaktadır (16).

İnce barsak obstrüksiyonları enteroklizisin major endikasyonlarından biridir (17, 18). Etiyolojinin saptanmasinda, itinali olarak uygulanan konvansiyonel ince barsak pasaj grafileri yardımcı olmakla birlikte tetkikte ince barsağın yetersiz distansiyonu nedeniyle başarı oranı düşüktür $(18,19)$. Yeterli distansiyonun elde edildiği enteroklizis yöntemi ise, intermittan ve parsiyel ince barsak obstrüksiyonlarında, en ideal yöntem olarak kabul edilmektedir (19, 20). Enteroklizisin obstrüksiyonlu olgular- da bir diğer avantajı da, kateter aracılığı ile tetkik sonrası dekompresyonun sağlanabilmesidir. Ancak yüksek dereceli veya komplet obstrüksiyonlarda, erken cerrahi girişim gerektiğinden, baryumlu tetkikler tercih edilmemektedir. Peristaltik aktivite yokluğu nedeniyle, ileri dönem obstrüksiyonlarda, baryumun lezyon seviyesine ulaşması da uzun sürmektedir. Bu tür obstrüksiyonlarda söz konusu olabilecek gangren kuşkusunda baryum kontrendike olduğundan tanıda BT'den yararlanılmaktadır $(21,22)$.

Çalışmamızda subileus ön tanısı ile incelediğimiz olgunun değerlendirmesinde obstrüksiyona işaret edecek bulgu saptanmadı. Motilideki azalmanın ve hastanın şikayetlerinin üç yıl önce yapılan bilateral trunkal vagotomiye sekonder olarak değerlendirildi.

İnce barsak tümörlerinin semptomları sıklıkla nonspesifik olduğundan tanı geç konmaktadır. Baryumlu tetkiklerin amacı lezyonun saptanması, morfolojisinin ve lokalizasyonunun belirlenmesidir. İnce barsağın primer ve sekonder tümörlerinin tanısı, küçük dolum defektleri ile intra veya ekstramural kitlelerin saptanmasi, barsak anslarının enteroklizis yöntemi ile distandü olduğu durumlarda, özellikle ileuma lokalize lezyonlarda, konvansiyonel pasaj grafilerine göre daha başarılı olmaktadır $(13,23)$.

Bessette ve ark., literatürde konuyla ilgili en geniş seriyi oluşturan 71 ince barsağın primer malign tümörlü olgusundaki çalışmalarında, tümöre bağlı değişikliğin saptanmasındaki sensitiviteyi takip ince barsak pasaj grafilerinde $\% 61$, enterokliziste ise $\% 95$ olarak bildirmektedir. Tümörün gösterilmesindeki sensitiviteleri ise sırası ile $\% 33$ ve \%90'dır (11).

İnce barsak tümörleri (primer veya sekonder) enteroklizis tetkikinde; kısa segment tutulumlu, lümen irregülaritesi gösteren iyi sınırlı dar segmentler (elma koçanı), polipoid dolum defektleri, ülsere kitle, barsak anslarına ekstrensek bası bulgusu şeklinde görülebilmektedir. Sağ alt kadran ağr1- 
sı ile değerlendirmeye aldığımız hastanın enteroklizis incelemesinde izlenen terminal ileumdaki rijidite ve mukozal düzensizliğin, daha sonra yapılan incelemelerde saptanan çekum karsinomunun teminal ileuma invazyonuna sekonder olduğu anlaşıldı. Kilo kaybı ve karın ağrısı nedeni ile incelemeye alınan başka bir olgumuzda kateterizasyon sirasinda duodenum seviyesinde karşılaşılan zorluk nedeni ile ince barsak değerlendirmesinin bitimini takiben kataterin geri çekimi sırasında mide ve duodenum grafileri alındı. $\mathrm{Bu}$ grafilerde izlenen duodenum 1 . ve 2 . kısmındaki eksternal bası bulgusunun daha sonraki incelemelerde saptanan pankreas başı lokalizasyonundaki kitle ve karaciğer metastazlarına sekonder olduğu anlaşıldı.

Primer ince barsak lenfomasının, sekonder tutulumdan ayırıcı tanısını radyolojik olarak yapmak mümkün değildir. İnce barsak lenfoması enteroklizis incelemesinde; duvar kalınlığında artış sonucu barsak ansları arasında seperasyon, foldlarda kalınlaşma, ileri dönemde foldlarda silinme ve lümende genişleme/daralma bulgularını gösterebilir (11). İntestinal lenfomanım araşt1rıldığı olgumuzun enteroklizis incelemesinde; mukozal foldlarda kalınlaşma ve lümen çapında artış izlendi. Patolojik değerlendirme sonucu lenfoma ile uyumlu idi.

Tüberküloz, ince barsakları sıklıkla sekonder olarak tutan ve en sık ileoçekal bölgeye yerleşen bir hastalıktır. Radyolojik bulgular hastalığın dönemi ile korelasyon gösterir. En erken değişiklikler mukozal paternde bozulma ve distal ileum kesimlerinde nodülaritedir. Akut dönemde ülsere segmentte spazm dominant bulgudur. Ülserler tipik olarak transaksiyel olup iyileşirken annüler striktürlere yol açarlar. Çalışmamızda kronik karın ağrısı şikayeti olan klinik ve radyolojik olarak Crohn hastal1ğ1 düşünülen hastanın enteroklizis incelemesinde ince barsak segmentlerinde seperasyon ve terminal ileumda düzensiz konturlu daralma saptandi. US ve BT incelemelerinde saptanan diğer bulgular nedeni ile tüberküloz açısın- dan araştırılan hastanın patolojik değerlendirme sonucu mezenterik tüberküloz ile uyumlu bildirildi. Enterokliziste saptanan seperasyon ve terminal ileumdaki daralmanın tüberküloz abselerinin yol açtığı basıya ait olduğu anlaşıldı.

Enteroklizis tetkikinin üst gastrointestinal sistemin ve kolonun radyolojik incelemesinde pozitif bulgu saptanmayan gastrointestinal kanamalarında değeri vurgulanmaktadır (24). Çocuklarda Meckel divertikülü, erişkinlerde anjiodisplazi en sık gastrointestinal kanama nedenidir. Enteroklizis ile Meckel divertikülünün ve diğer ince barsak divertiküllerinin tanısı, diğer yöntemlere göre daha tutarlı bir şekilde sağlanmaktadır $(25,26)$.

Behçet hastalığı, rekürren oral aftöz ülserler, oküler lezyonlar, deri erüpsiyonları ve genital ülserler ile karakterize, kronik, idiopatik, sistemik bir hastalıktır. Behçet hastalığı, gastrointestinal segmentte en sık terminal ileum ve çekumu tutar. İleum ve çekumda multipl, farklı derinlik ve boyutta ülserler, ileri dönemde striktürler görülür. Bu ülserler perfore olma eğilimindedir.Çalışmamızda entero-Behçet tanısı ile izlenen ve özgeçmişinde ileal segmentlerdeki ülserlere sekonder ince barsak perforasyonu nedeni ile laparatomi uygulanan olguya kontrol amaciyla uygulanan enteroklizis incelemesinde, terminal ileumun rezeke edilmiş ve rezidü ileal segmentlerin çıkan kolon orta kesimine ağızlaştırılmış olduğu saptandi.

Tüm diğer tetkiklerde olduğu gibi enteroklizisde de bazı potansiyel komplikasyonlar mevcuttur. Ciddi komplikasyonlar kateterizasyon esaslarının uygulanması ve farklı infüzyon hızlarına ince barsağın cevabının kavranması ile önlenebilir.

Duodenal sondanın kateterizasyonu sırasinda mukozal disseksiyon ve perforasyon gibi major komplikasyonlar açısından dikkatli olunmalıdır. Kılavuz tel kateter içerisinde ve kateter ucunun biraz proksimalinde tutulmalıdır. Duodenumdan veya herhangi bir kiv- rımdan geçiş esnasında rehber tel kateter ucundan $4-5 \mathrm{~cm}$. geriye çekilmelidir. Anatomik kıvrımlardan rahatlıkla geçilemediği durumlarda kuvvet veya zorlama uygulanmamalı, suda eriyebilen bir kontrast materyal enjekte ederek tüp pozisyonu değerlendirilmelidir. Kılavuz tel kateterin distal ucundan ileriye itilmemeli ve kateterin distal ucundaki deliklerden dişarı çıkmamalıdır. Bu koşullarda gastrointestinal mukozanın maruz kalabileceği travma, mural penetrasyon ve perforasyon riski azdır. Literatürde enteroklizis komplikasyonu olarak sadece 1 özofageal, 1 duodenal ve 1 ileal perforasyon olgusu bildirilmektedir $(13,20)$.

Minor komplikasyonlar ise nadir değildir. Olguların yaklaşık \%10'unda midede substansiel reflü ve llık olmayan kontrast kullanımına bağlı olarak gelişen kusma, tetkik öncesinde proflaktik olarak IV antiemetik ajan, balonlu kateter ve uygun isı ve hizda kontrast madde kullanılması ile önlenebilmektedir. Diğer minör komplikasyonlar arasında metil sellüloz infüzyonu sırasında karında kramp tarzında ağrı, entübasyonda refleks olarak zorlanma ve özellikle yaşlı ve genel durumu kötü hastalarda bronşial aspirasyon sayılmaktadır.

Çalışmamızda hiçbir olguda major komplikasyon gelişmemiştir. Bir olguda tetkik sırasında şiddetli bulantı-kusma oldu (\%44.4). Ancak antiemetik kullanımını gerektirmedi.

Enteroklizis tetkikinin kontrendikasyonları ise; komplet obstrüksiyonu olan hastalarda birlikte intestinal iskemi veya infarktın varlığı, spesifik nedenlere bağlı veya reflü sonucu gelişen özofajitlerdir. Mide operasyonu geçirmiş hastalarda da ilk 2 hafta içinde enteroklizis yapılmamalıdır. Üst gastrointestinal traktta ülserasyon veya büyük kitlelere bağlı gelişen striktürlerde de perforasyon riskinden dolayı baryum verilmeden önce pnömoperitoneum olasılığ1 direkt grafi tetkikleri ile ekarte edilmelidir. Obstrüksiyonlu olgularda enteroklizisin tek kontrendikasyonu, kuşkulu perforasyon veya kolonda 
yüksek olasılıklı obstrüksiyondur (19).

Sonuç olarak enteroklizisin ince barsakların normal olduğu durumları ortaya koymada güvenilirliği yüksektir. İntermittan ve parsiyel ince barsak obstrüksiyonlarının yeri, derecesi ve sebebinin belirlenmesinde enteroklizisin çok değerlidir. İnflamatuar patolojiler, adeziv bantlar ve tümörler gibi fokal lümen daralmaları, bu teknikle tanınabilirler. Enteroklizis tetkiki ile neoplazi tanısı belirlenen olgular, ekstraluminal yapıların değerlendirilmesi amacı ile $\mathrm{BT}$ ve US ile de incelenmelidir. Crohn hastalığnın erken dönem tanısında, tanı aşamasından sonra da hastalığın yaygınlığı, derecesi ve komplikasyonları- nın belirlenmesinde enteroklizis üstün bir yöntemdir. Takip ince barsak pasaj grafileri diagnostik amaçla kullanılabilir, ancak hastalıkta mukozal lezyonların ve şiddetinin belirlenmesinde enteroklizis tekniği daha başarılıdır. Çevre yağ dokusu infiltrasyonu, abse ve LAP tanısında ise BT'nin katkısına gereksinim vardır. Klinik malabsorpsiyon tanısını radyolojik olarak desteklemede ve etiolojinin demonstrasyonunda enteroklizis seçilecek yöntemdir. Üst gastrointestinal sistem ve kolonun endoskopik ve radyolojik incelemesi ile etiolojinin saptanamadığı gastrointestinal sistem kanamalarında ince barsakların enteroklizis ile incelenmesi tanıda değerlidir.
Teknik açıdan manipülasyon gerektirdiğinden, konvansiyonel pasaj grafilerine göre zor bir yöntem olan enteroklizis, nadir de olsa perforasyon ve mukozal disseksiyon gibi ciddi komplikasyon riski taşımaktadır. Usulüne uygun ve dikkatli çalışıldığında bu risk hemen hemen tüm olarak ortadan kalkmaktadır.

Endoskopik ve radyolojik inceleme olanaklarının sınırlı olduğu ince barsaklarda, teknik açıdan nispeten güç olan enteroklizisin, bu organ hastalıklarının tanı ve ayırıcı tanısında üstün bir inceleme yöntemi olduğu sonucuna varilmıştır. 


\section{KAYNAKLAR}

1. Sellink JL. Thoughts on the radiologic study of the small intestine. Ned Tijdschr Geneeskd. 1971 Apr 24;115(17):743-8.

2. Herlinger H. A modified technique for the double-contrast small bowel enema. Gastrointest Radiol. 1978 Jun 25;3(2):201-7.

3. Gurian L, Jendrzejewski J, Katon R, et al. Small-bowel enema. An underutilized method of small-bowel examination. Dig Dis Sci. 1982 Dec;27(12):1101-8.

4. Johnson D. World literature review: Celiac disease: Biopsy or enteroclysis beter for evaluating response to a gluten free diet? Am J Gastroenterol. 1997; 92: 715-716

5. van den Bosch HC, Tjon a Tham RT, Gooszen AW, et al. Celiac disease: small-bowel enteroclysis findings in adult patients treated with a gluten-free diet. Radiology. 1996 Dec;201(3):803-8.

6. Herlinger H. Radiology in malabsorption. Clin Radiol. 1992 Feb;45(2):73-8.

7. Maglinte DD, Chernish SM, Kelvin FM, et al. Crohn disease of the small intestine: accuracy and relevance of enteroclysis. Radiology. 1992 Aug;184(2):541-5.

8. Carlson HC. Perspective: the small bowel examination in the diagnosis of Crohn's disease. AJR Am J Roentgenol. 1986 Jul;147(1):63-5.

9. Bernstein CN, Boult IF, Greenberg HM, et al. A prospective randomized comparison between small bowel enteroclysis and small bowel follow-through in Crohn's disease. Gastroenterology. 1997 Aug;113(2):390-8.
10. Maglinte DD, Burney BT, Miller RE. Lesions missed on small-bowel follow-through: analysis and recommendations. Radiology. 1982 Sep;144(4):737-9.

11. Gore RM. Textbook of Gastrointestinal Radiology, WB Saunders Company $1994 \mathrm{Vol}$ 2, Section VII, VIII.

12. Herlinger $\mathrm{H}$. The small bowel enema and the diagnosis of Crohn's disease. Radiol Clin North Am. 1982 Dec;20(4):721-42.

13. Maglinte DD, Hall R, Miller RE, et al. Detection of surgical lesions of the small bowel by enteroclysis. Am J Surg. 1984 Feb;147(2):225-9.

14. Bender GN, Maglinte DD, Klöppel VR, et al. CT enteroclysis: a superfluous diagnostic procedure or valuable when investigating small-bowel disease? AJR Am J Roentgenol. 1999 Feb;172(2):373-8.

15. Maglinte DD, Sandrasegaran K, Lappas JC, et al. CT Enteroclysis. Radiology. 2007 Dec;245(3):661-71.

16. Masselli G, Casciani E, Polettini E, et al. Comparison of MR enteroclysis with MR enterography and conventional enteroclysis in patients with Crohn's disease. Eur Radiol. 2008 Mar;18(3):438-47. Epub 2007 Sep 25.

17. Massoud TF, Creasy T, Nolan DJ. Contrast radiography in small-bowel obstruction: enteroclysis forgotten? Surgery. 1991 Mar;109(3 Pt 1):345-6.

18. Caroline DF, Herlinger H, Laufer I, et al. Small-bowel enema in the diagnosis of adhesive obstructions. AJR Am J Roentgenol. 1984 Jun;142(6):1133-9.
19. Maglinte DD, Peterson LA, Vahey TN, et al. Enteroclysis in partial small bowel obstruction. Am J Surg. 1984 Mar;147(3):325-9.

20. Maglinte DD, Lappas JC, Kelvin FM, et al. Small bowel radiography: how, when, and why? Radiology. 1987 May;163(2):297305.

21. Frager D, Medwid SW, Baer JW, et al. CT of small-bowel obstruction: value in establishing the diagnosis and determining the degree and cause. Am J Roentgenol. 1994 Jan;162(1):37-41.

22. Maglinte DD, Gage SN, Harmon BH, et al. Obstruction of the small intestine: accuracy and role of CT in diagnosis. Radiology. 1993 Jul;188(1):61-4.

23. Gourtsoyiannis NC, Bays D, Papaioannou $\mathrm{N}$, et al. Benign tumors of the small intestine: preoperative evaluation with a barium infusion technique. Eur J Radiol. 1993 Feb;16(2):115-25.

24. Rex DK, Lappas JC, Maglinte DD, et al. Enteroclysis in the evaluation of suspected small intestinal bleeding. Gastroenterology. 1989 Jul;97(1):58-60.

25. Maglinte DD, Chernish SM, DeWeese $\mathrm{R}$, et al. Acquired jejunoileal diverticular disease: subject review. Radiology. 1986 Mar;158(3):577-80.

26. Maglinte DD, Elmore MF, Isenberg M, et al. Meckel diverticulum: radiologic demonstration by enteroclysis. AJR Am J Roentgenol. 1980 May;134(5):925-32. 